\title{
The evaluation of oxidative stress in osteoarthritis
}

\author{
Oana-Maria Zahan, Oana Serban, Claudia Gherman, Daniela Fodor
}

RHEUMATOLOGY

$2^{\text {nd }}$ Internal Medicine Department, Iuliu Hatieganu University of Medicine and Pharmacy, ClujNapoca, Romania
DOI: $10.15386 / \mathrm{mpr}-1422$

Manuscript received: 17.07.2019

Received in revised form: 02.10.2019

Accepted: 16.10.2019

Address for correspondence:

dfodor@umfcluj.ro

This work is licensed under a Creative Commons Attribution-NonCommercialNoDerivatives 4.0 International License

\begin{abstract}
Osteoarthritis (OA) is a whole joint disease driven by abnormal biomechanics and attendant cell-derived and tissue-derived factors. The disease is multifactorial and polygenic, and its progression is significantly related to oxidative stress and reactive oxygen species (ROS). Augmented ROS generation can cause the damage of structural biomolecules of the joint and, by acting as intracellular signaling component, ROS are associated with various inflammatory responses. By activating several signaling pathways, ROS have a vital importance in the patho-physiology of OA. This review is focused on the mechanism of ROS which regulate intracellular signaling processes, chondrocyte senescence and apoptosis, extracellular matrix synthesis and degradation, along with synovial inflammation and dysfunction of the subcondral bone, targeting the complex oxidative stress signaling pathways.
\end{abstract}

Keywords: inflammation, oxidative stress, anti-oxidant enzyme, osteoarthritis, ROS

\section{Introduction}

Arthritis is a chronic joint disease leading to cartilage degradation that involves synovial inflammation, subchondral bone remodeling and the formation of osteophytes [1,2]. Cartilage degradation results from ruptured joint homeostasis that favors catabolic processes. These processes are activated by pro-inflammatory mediators such as cytokines, lipid mediators and reactive oxygen species (ROS), which are produced also by chondrocytes, synoviocytes and osteoblasts [3,4]. These products are responsible for battering anabolism and release of proteolytic enzymes, degrading the extracellular matrix.

The definition of oxidative stress as a disturbance in the pro-oxidant/antioxidant balance in favor of the former [5] implies that this disturbance can be corrected by the addition of appropriate anti-oxidants. Redox mechanisms have been shown to influence intracellular signaling and cells seem to be very sensitive to the loss of these regulatory and control systems $[6,7]$.

Previous studies demonstrated that osteoarthritis (OA) progression is significantly related to oxidative stress and ROS $[8,9]$. OA is characterized by morphological, biochemical, molecular and biomechanical changes of both cells and extracellular matrix (ECM) which leads to softness, loss of articular cartilage, synovial inflammation, sclerosis of subchondral bone, formation of osteophytes and subchondral cysts (Figure 1).

In this review we aim to summarize the knowledge about the contribution of the oxidative stress signaling pathways to OA pathobiology.

\section{Mechanical stress}

Under normal physiological conditions, the synovial space is one of the most pressurized areas of the body. Classical stress factors are present in the synovial cavity, and these stimuli are likely to influence the functions of the synovial membrane cells. Like the blood vessels walls, the synovial cavity is exposed to a high degree of mechanical stress in normal and pathological conditions. In addition to mechanical stresses, there is also oxidative stress that follows the cutting forces. In particular, the movement of the synovial fluid induces shear forces whose biophysics has been studied in detail [10-12]. Because the cells transduce mechanical stress into biochemical signals, many cellular functions can be affected by the presence of mechanical stress. 


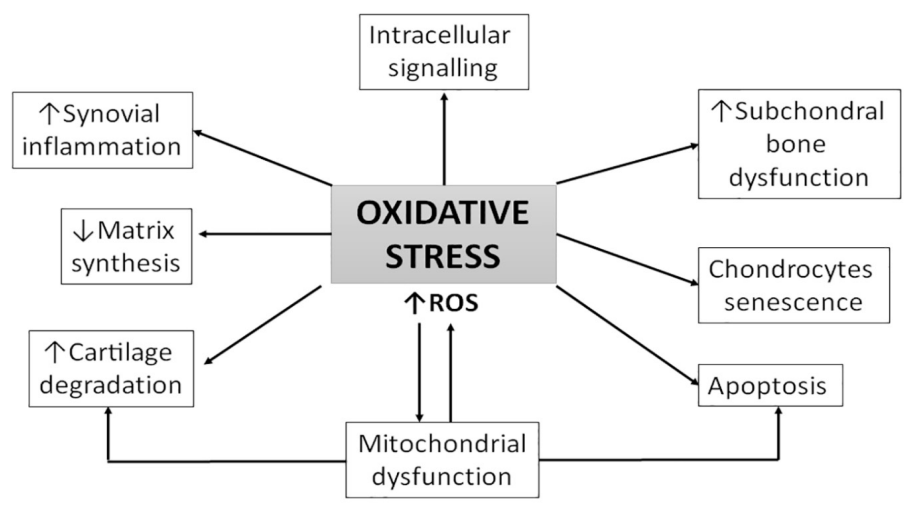

Figure 1. Mechanism of OA pathogenesis related with oxidative stress. ROS- reactive oxygen species.

\section{The ROS signaling pathway}

ROS are free radicals containing oxygen molecules including hydroxyl radical $\left(\mathrm{OH}^{-}\right)$, hydrogen peroxide $\left(\mathrm{H}_{2} \mathrm{O}_{2}\right)$, superoxide anion $\left(\mathrm{O}_{2}^{-}\right)$, nitric oxide $\left(\mathrm{NO}^{-}\right)$and hypochlorite ion $\left(\mathrm{OCl}^{-}\right)$. The presence of unpaired electrons in the valence shell causes ROS to be short-lived, unstable and highly reactive in order to achieve stability. Of these, the most likely source is mitochondria: it is estimated that $2-3 \%$ of the total $\mathrm{O}_{2}$ consumed by functional mitochondrial electron transport chains is incompletely reduced to the $\mathrm{O}_{2}^{-}$, rather than to water. The NADPH oxidase enzymes (NOXes) are the major sources of ROS in phagocytes through the reaction $2 \mathrm{O}_{2}+\mathrm{NADPH} \rightarrow 2 \mathrm{O}_{2}^{-}+\mathrm{NADP}^{+}+\mathrm{H}^{+}$. Upon stimulation, cytosolic components translocate to the inner face of the plasma membrane to form a fully active enzyme complex that possesses NADPH oxidase activity. A similar process is believed to take place in non-phagocytic cells as well. $\mathrm{XO}$ catalyzes the oxidation of hypoxanthine to xanthine, producing $\mathrm{H}_{2} \mathrm{O}_{2}[13,14]$.

The major sites of ROS production include the mitochondria - through oxidative phosphorylation, nonmitochondrial membrane-bound nicotinamide adenine dinucleotide phosphate (NADPH) oxidase and xanthine oxidase (XO) [14-16].

Extensive mechanisms for scavenging ROS have evolved into species that utilize oxygen for energy production. This antioxidant system includes enzymatic and non-enzymatic antioxidants, such as superoxide dismutase (SOD), catalase (CAT), glutathione peroxidase (GPX), glutathione (GSH), NADPH ubiquinone oxidoreductase $\left(\mathrm{NQO}_{1}\right)$, paraoxanases $(\mathrm{PON})$, ascorbic acid (vitamin $\left.\mathrm{C}\right)$, alfa-tacopherol (vitamin E) and carotinoid $[17,18]$.

The free radical $\mathrm{NO}^{-}$is produced by a number of different cell types with a variety of biological functions. $\mathrm{NO}^{-}$is a product of the oxidation of $\mathrm{L}$-arginine to $\mathrm{L}$-citrulline in a two steps process catalysed by the enzyme nitric oxide synthase (NOS). Three major isoforms of NOS have been identified. The constitutive isoforms found in neurons and endothelial cells, namely neuronal NOS (nNOS) and endothelial NOS (eNOS), produce very low amounts of NO in a calcium- and calmodulin-dependent fashion. The inducible isoform of the enzyme (iNOS), is expressed for a longer period of time, requires minimal concentrations of calcium, produces NO in relatively large amounts in response to proinflammatory cytokines lipopolysaccharide (LPS), interleukin-1 (IL-1), tumoral necrosis factor- $\alpha$ (TNF$\alpha$ ), interferon- $\gamma($ IFN- $\gamma$ ) and acts in a host defensive role through its oxidative toxicity. Regardless of the source/role, NO reacts with several different molecules that are normally present to form either nitrate $\left(\mathrm{NO}_{3}^{-}\right)$or nitrite $\left(\mathrm{NO}_{2}^{-}\right)$[19]. Reactive nitrogen species (RNS), a family of molecules derived from $\mathrm{NO}^{-}$and $\mathrm{O}_{2}^{-}$, are responsible of the nitrosative stress that act together with ROS in the process of cell damage [20].

\section{ROS function}

ROS are known to be a component of the killing response of immune cells to bacterial invasion. The stimulated production of ROS by phagocytic cells, catalyzed by NADPH oxidase, was originally called "the respiratory burst" because of the increased consumption of oxygen by these cells [21]. It is known that ROS are produced in all cell types and serve as important cellular messengers in normal signal transduction, gene regulation, and cell cycling [22].

ROS-induced cell signaling involves two general mechanisms: alterations in the intracellular redox state and oxidative modification of proteins. Cells respond to ROS in different ways depending on the intensity, duration, context of the signaling and cellular redox status. When the oxidant level does not exceed the reducing abilities of cells, ROS are involved in several physiological cellular functions including signal transmission [22]. It is now apparent that a very complex intra-cellular regulatory system involving ROS exists within cells [23].

After its production, ROS mediates its biological activities, which can be divided into three categories. 
Firstly, ROS reacts with transition metals $(\mathrm{Fe}, \mathrm{Cu}$, $\mathrm{Zn}$ ), which are abundant in prosthetic groups of enzymes, regulating their activity. NO activates soluble hemecontaining cyclic guanylate cyclase (sGC) to produce activated cyclic guanosine monophosphate (cGMP) from guanosine triphosphate (GTP). cGMP acts a second messenger as it specifically binds to target proteins which include cGMP-dependent protein kinases (PKG), cAMPdependent protein kinases phosphodiesterases (PDEs) and cyclic nucleotide-gated channels to elicit a number of biological effects [24,25]. Simultaneously, NO inhibits $\mathrm{Cu}-$ containing cytochrome P-450 enzymes and cytochrome c oxidase in mitochondria, and Fe-containing CAT, resulting in a reduction of the electron transport chain favoring the formation of $\mathrm{O}_{2}^{-}$and $\mathrm{H}_{2} \mathrm{O}_{2}$ [26].

Secondly, ROS can also bind to a reactive cysteine thiol to form S-nitrosothiols, which are very important regulators of physiology and pathology, affecting the activity of enzymes and transcription factors, such as NF$\kappa \mathrm{B}, \mathrm{AP}-1, \mathrm{p} 21$ kinase, c-Jun N-terminal kinases (JNKs), caspase-3 and caspase- 9 , through prevalent post-translational protein modification [27]. Under physiologic conditions, protein S-nitrosylation and S-nitrothiosols provide protection preventing further cellular oxidative and nitrosative stress.

Thirdly, ROS production in an oxidizing environment, as when $\mathrm{O}_{2}^{-}$is present, leads to the rapid formation of reactive molecules such as peroxynitrite $\left(\mathrm{ONOO}^{-}\right)$. $\mathrm{ONOO}^{-}$is rapidly decomposed to $\mathrm{NO}_{2}$ and $\mathrm{OH}^{-}$and all together they react with other molecules and radicals. At cellular $\mathrm{pH}, \mathrm{ONOO}^{-}$is protonated to form peroxynitrous $(\mathrm{ONOOH})$ which is very cytotoxic, causing depletion of - SH groups, oxidation of lipids, DNA strand breakage and deamination of DNA bases [25]. NO can also act in a cGMP-independent manner, by directly modifying proteins or contributing to the oxidation of proteins and lipids, further increasing the complexity and number of potential roles for NO in cellular functions [28].

\section{ROS signaling in OA cartilage}

Besides other agents - risk factors such as overweight or a family history, oxidative stress is involved in the pathogenesis of OA. OA is not limited to articular cartilage only, but also affects the subchondral bone, as well as the adjacent connective tissue and the synovial membrane. The involvement of free radicals in signal transduction highlighted that, within evolution, higher life forms took advantage of the ability of ROS to mediate signals over cell margins in a system consisting of discrete compartments like joints. Because of their chemical properties, free radicals meet the requirements to mediate and amplify the characteristic sequence of joint degeneration in all tissues affected. ROS are crucial factors in the OA pathophysiology and the sudden breakdown of compensation leading to inflammatory transformation of OA joints.

\section{ROS production in chondrocytes}

ROS are produced at low level in chondrocytes, mainly by NADPH oxidase, and they act as integral actors of intracellular signaling mechanisms, contributing to the maintenance of cartilage homeostasis as they modulate chondrocyte apoptosis, gene expression, extracellular matrix (ECM) synthesis/breakdown and cytokine production [29-33] (Figure 2).

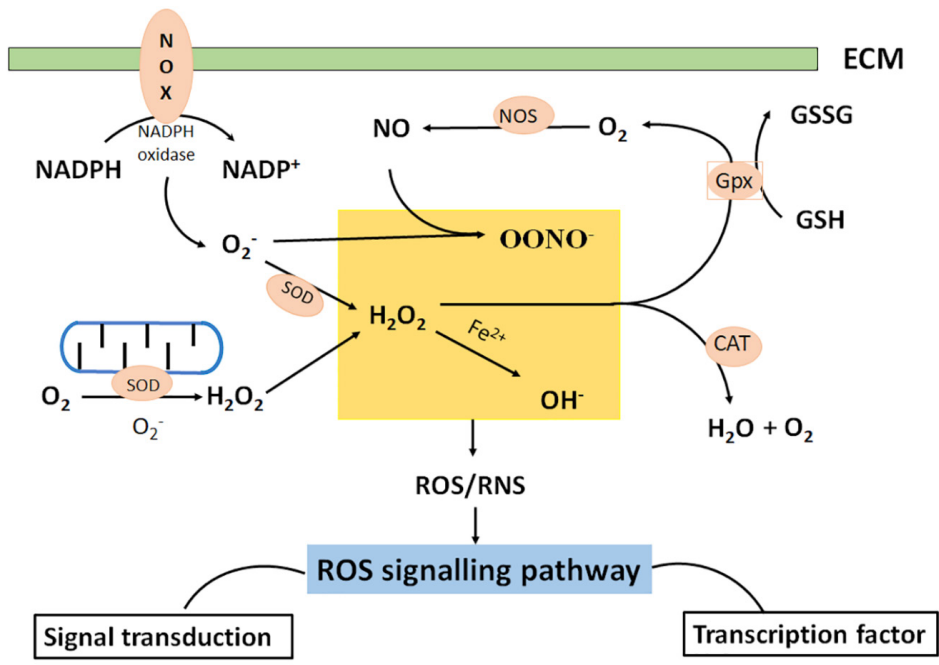

Figure 2. Sites of cellular reactive oxygen species (ROS) in chondrocytes include mitochondria and NADPH oxidase (NOX). ROS include radical species, such as superoxide $\left(\mathrm{O}_{2}^{-}\right)$and hydroxyl radical $\left(\mathrm{HO}^{-}\right)$and non-radical species such as hydrogen peroxide $\left(\mathrm{H}_{2} \mathrm{O}_{2}\right)$. After the superoxide production in mitochondria, the super oxide dismutase (SOD) dissipates superoxide producing $\mathrm{H}_{2} \mathrm{O}_{2}$ and $\mathrm{O}_{2}$. The reaction of divalent iron ions with $\mathrm{H}_{2} \mathrm{O}_{2}$ produces $\mathrm{HO}^{-}$. Nitric oxide $\left(\mathrm{NO}^{-}\right)$produced by nitric oxide synthase (NOS) and mediates physiological processes of ROS. $\mathrm{NO}^{-}$is highly reactive with free radical species like $\mathrm{O}_{2}^{-}$which reacts with $\mathrm{NO}^{-}$to produce $\mathrm{ONOO}^{-}$which is highly oxidizing. Catalase (CAT), located in peroxisome, is another enzyme responsible for $\mathrm{H}_{2} \mathrm{O}_{2}$ removal. Glutathione peroxidase (Gpx) catalyzes the conversion of reduced glutathione (GSH) to oxidized glutathione (GSSG), but also converts $\mathrm{H}_{2} \mathrm{O}_{2}$ to $\mathrm{O}_{2}$. 
ROS production and oxidative stress were found elevated in patients with OA [34-36]. Evidence for ROS implication in cartilage degradation came from the presence of lipid peroxidation products, such as oxidized low-density lipoprotein (ox-LDL), nitrite $\left(\mathrm{NO}_{2}^{-}\right)$, nitrotyrosine, and nitrated $\left(\mathrm{NO}_{3}^{-}\right)$products in the biological fluids and the cartilage of OA patients with and in OA animal models [28,32-35]. On the contrary, antioxidant enzymes, such as superoxide dismutase (SOD), catalase (CAT), glutathione peroxidase (GPX) were decreased in OA patients, confirming the role of oxidative stress in OA pathogenesis [30,31,36-40].

Superoxide anion radicals are produced by NADPH oxidase, whose components are expressed in human articular chondrocytes [41-43]. It was demonstrated that the porcine articular chondrocytes can release ROS using the NADPH oxidase-like complex [40]. NADPH oxidase expressed by chondrocytes is the main enzyme responsible for ROS formation in synovial fluid, contributing to increased oxidative stress inside the joint and mediating the progressive cartilage degradation of OA [42-45].

Nitric oxide synthase isoform (iNOS) is mainly expressed in human chondrocytes [44]_and its expression is upregulated by inflammatory cytokines, such as interleukin-1 $\beta$ (IL-1 $\beta$ ), interleukin-17 (IL-17), tumor necrosis factor- $\alpha$ (TNF- $\alpha$ ), interferon- $\gamma$ (IFN- $\gamma$ ), and shear stress [46]. Chondrocytes from OA cartilage overexpress NOS particularly in the superficial zone, suggesting that these tissues are actively producing iNOS [47]. The role of NOS in OA pathogenesis is supported by the fact that NOS knockout mice do not develop experimental OA [48].

Apart from iNOS, another NOS isoform, neuronal nitric oxide synthase (nNOS), which produces lower amounts of NO, was found to be constitutively expressed in bovine chondrocytes and to be degraded in response to IL-1. The presence of a protein similar in size and antibody binding to nNOS, but with enzymatic activity of iNOS has been reported in human OA chondrocytes. Since NO is recognized as a major factor in OA progression, iNOS inhibitors have been considered as potential candidates for disease modification. It is known that selective inhibition of iNOS retards the progression of experimental arthritis. There is a study that investigated the clinical utility of selective iNOS inhibitors as disease-modifying OA drugs, as they have been shown to reduce joint inflammation and erosion in animal models of OA. The same study demonstrated that nNOS is more frequently expressed by normal chondrocytes, while iNOS prevails in OA chondrocytes [49].

Chondrocytes are quiescent and lack self-renewal capacity. Chondrocyte death is regarded as a major factor in OA pathogenesis and oxidative stress seems to play a major role through chondrocyte apoptosis [50]. Apoptosis is a complex intracellular pathway resulting from the equilibrium between apoptotic and non-apoptotic factors and processes [51]. The mechanism of apoptosis are divided into the intrinsic or mitochondrial pathway, which is induced by intracellular signals, and the extrinsic or death receptor pathway, which is triggered by the extracellular signals, including activation of the death receptor family. However, the two apoptosis pathways are interconnected through the mitochondria.

The extrinsic pathway involves transduction of the apoptotic signal after the binding of death receptors, such as Fas, TNF receptor 1 (TNFR1) or TNF-related apoptosis inducing ligand (TRAIL) receptor R1 and R2, to their ligands FasL, TNF and TRAIL.

Excess production of ROS and NO has been linked with apoptosis of cartilage chondrocytes both in vitro and in vivo and apoptotic chondrocytes in OA are reported to contain 3-nitrotyrosine [52,53].

$\mathrm{H}_{2} \mathrm{O}_{2}$ induces chondrocyte cell death in a dosedependent way [54]. ROS induces chondrocyte apoptosis through regulation of $\mathrm{PI} 3 \mathrm{~K} / \mathrm{Akt}$ and $\mathrm{JNK}$ signaling pathways. Increased oxidative stress makes chondrocytes more susceptible to oxidant-mediated cell death though the deregulation of the glutathione antioxidant system [55]. $\mathrm{H}_{2} \mathrm{O}_{2}$ generated by the hypoxanthine-xanthine oxidase (XOD) system leads to inhibition of growth of articular chondrocytes. In addition, a product of lipid peroxidation causes human chondrocyte death by activating caspase-3, -9 and suppressing pro-survival AKT kinase activity [56].

The precise role of $\mathrm{NO}$ in the induction of chondrocyte death is repeatedly disputed. NO is the primary inducer of chondrocyte apoptosis, mediated by caspase-3, caspase- 9 and tyrosine kinase activation which cause iNOS upregulation [57-59], but the action of $\mathrm{ONOO}^{-}$is also required [60].

Addition of $\mathrm{ONOO}^{-}$to articular chondrocytes has been found to lead to apoptotic death. NO-induced apoptosis of chondrocytes depends on the crosstalk between iNOS and COX-2 systems, which is linked to the activation of MEK1/2 and p38 pathways. However, production of high levels of endogenous NO by overexpression of the iNOS gene in transfected chondrocytes has not been found to cause cell death [60]. This discrepancy might be the result of using chemical NO donors, which produce various secondary reactions depending on the cellular milieu in in vitro experiments.

Sodium nitroprusside (SNP) is generally regarded as the donor of NO to study the mechanism of chondrocyte NO-induced apoptosis [61]. In vitro, SNP induces apoptotic events in chondrocytes by increasing caspase-3 and caspase-7 expression and downregulating $\mathrm{Bcl}-2$ expression [62]. It has been found that in human chondrocytes, SNP induces DNA fragmentation, cytoskeletal remodeling, mitochondrial dysfunction, caspase activation and cytochrome $\mathrm{C}$ release, all of which are apoptotic events [63].

NO also appears to mediate chondrocyte apoptosis driven by chronic mechanical overloading of joints. In 
response to chronic mechanical overloading, both in vivo and in vitro, chondrocytes generate high levels of NO, and this production depends on the oxygen tension within articular cartilage [64,65]. However, it is important to note that SNP binds to oxyhemoglobin to release NO.

On the other hand, other studies propose that $\mathrm{NO}^{-}$ is a physiologic regulator of mitochondrial respiration $[62,64]$ or it may have an anti-protein activity, via the inhibition of as-induced caspase-3 activation, especially when intracellular antioxidant level is very low $[64,65]$. The pro-apoptotic effect of IL-1 $\beta$ does not depend on $\mathrm{NO}^{-}$ [65] and $\mathrm{NO}^{-}$mediated chondrocyte cell death demands the generation of additional ROS [37,66]. Apoptosis is a consequence of cell inactivation, following the induction of deoxyribonucleic acid (DNA) damage [67].

As both the predominant site for ROS production and the prime target of these molecules, mitochondria play a key role in oxidative stress and in OA pathogenesis. ROS cause mitochondrial respiratory chain inhibition, adenosine triphosphate (ATP) decrease, and mitochondrial DNA (mtDNA) mutation all of which are related to the severity of the inflammatory process as they enhance functional failure and cell death $[65,68,69]$ (Figure 3).

\section{Functions of ROS in the articular cartilage}

Chondrocytes comprise $2-5 \%$ of the cartilage volume, a tissue that is avascular and lacks innervation. In normal conditions, the adult articular chondrocyte is a resting cell, with no detectable mitotic activity, and adapted to an environment with low oxygen supply. For these reasons the intracellular metabolism is constant, and the turnover synthesis of ECM components is low. Despite the traditional opinion that chondrocytes live in an anaerobic environment, the superficial and middle zones of articular cartilage are not anoxic; oxygen does diffuse into articular cartilage, and articular chondrocytes possess mitochondria and breath in vitro, producing ROS [70].

In pathological situations, such as in OA, oxygen tension in synovial fluid is subjected to fluctuations because of ischemia-reperfusion phenomenon, pathological acceleration of tissue metabolism and sustained abnormal strains on the joint [71]. In response to partial oxygen pressure variations, mechanical stress $[55,72]$ and inflammatory mediators (IL- $1 \beta$, IFN- $\gamma$, ox-LDL, LPS, IL-17), the chondrocytes produce abnormal levels of ROS through NADPH oxidase, NOS and XO $[40,73,74]$.

In chondrocytes, ROS intermediates in multiple signaling pathways including those initiated by cytokines, growth factors and ECM proteins. The responses of the cells to cytokines and growth factors depend on the cell redox status which is a result of a subtle equilibrium between ROS production and the intracellular antioxidants level. This balance is subtly modulated by exogenous factors, such as oxygen tension or cytokines. In pathological circumstances, such as in OA, the redox status can be altered and the responses of the cells to biochemical factors can be fully modified $[75,76]$.

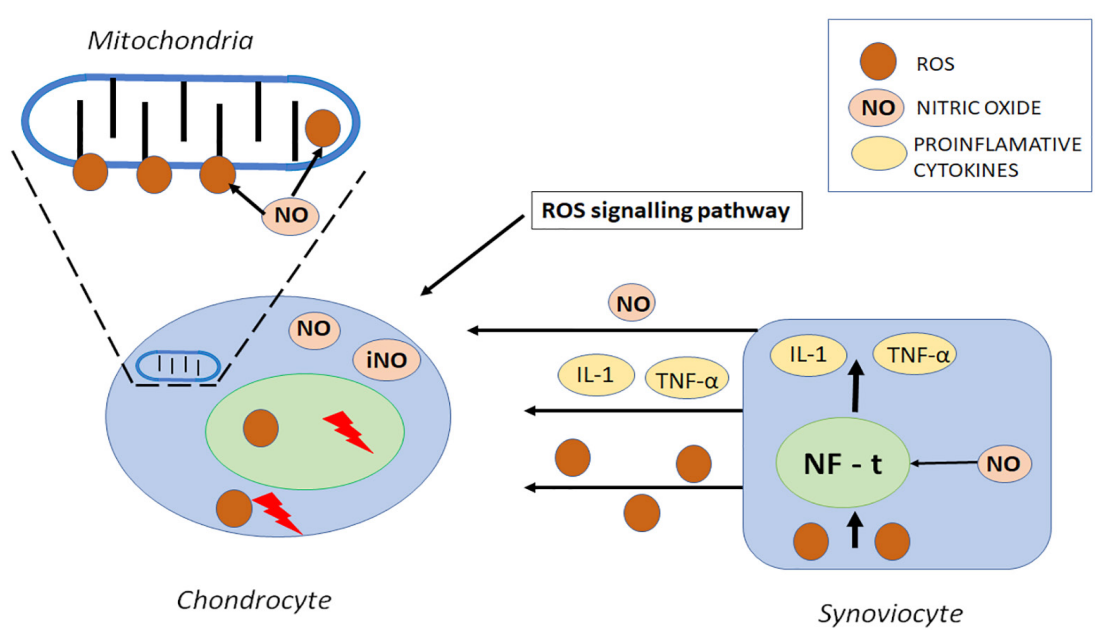

Figure 3. Structure of reactive oxidative molecules in mitochondrion. Disruption of chondrocytes by nitric oxide induced inhibition is involved in chondrocyte functional compromise. Nitric oxide $\left(\mathrm{NO}^{-}\right)$is released with several pro-inflammatory factors by synovial cells as a result of inflammatory transition. The nuclear transcription factor (NF-t) involved in the upregulation of several inflammatory genes is an important factor for the ROS/RNS induced inflammatory transition of synovial membrane, mainly by NO- related TNF- $\alpha$ and IL-1 induction damage of mitochondrial DNA. 
ROS have been implicated in the inhibition of new cartilage ECM synthesis, leading to loss of cartilage integrity. Cartilage ECM is primarily composed by type II collagen (COLII) and proteoglycans (PGs) [68]. In cultures of human articular chondrocytes, endogenously produced $\mathrm{O}^{-}$inhibited the synthesis of proteoglycans from both the superficial and deep cartilage zone. Inside chondrocytes, $\mathrm{H}_{2} \mathrm{O}_{2}$ suspends proteoglycan synthesis by suppressing the mitochondrial oxidative phosphorylation and adenosine triphosphate_(ATP) formation $[77,78]$. The concurrent generation of $\mathrm{O}_{2}^{-}$and $\mathrm{NO}^{-}$is required for IL-1 to inhibit proteoglycan synthesis [79]. Oxidative stress inhibits IGF-1 induction of chondrocyte proteoglycan synthesis through differential regulation of phosphatidyl inosite-3-kinase (PI3K/Akt) and extracellular signalregulated-kinase (MEK-ERK) signaling pathways $[50,80]$.

$\mathrm{NO}^{-}$is implicated in the IL-1-dependent inhibition of COLII and aggrecan synthesis [81]. NO- blocks biosynthesis of COLII at a post-translational level by activating prolyl hydroxylase and therefore inducing the hydroxylation of proline residues. This fact is counteracted by the presence of hyaluronic acid (HA) in synovial fluid which inhibits IL-1 $\beta$-stimulated $\mathrm{NO}^{-}$synthesis [82].

In terms of new cartilage synthesis, ROS contribute to the loss of chondrocyte sensitivity to growth factors [83]. ROS may also participate in the failure to recover by reducing the capacity of chondrogenic precursor cells to migrate and proliferate within an injured area [79]. Similarly, $\mathrm{NO}^{-}$has been demonstrated to inhibit chondrocyte migration and attachment to fibronectin via modification of the actin cytoskeleton [84].

\section{ROS signaling in synovial inflammation}

The inflammatory reaction in synovium is controlled by several biochemical factors, including prostanoids, cytokines (IL-1 $\alpha$, IL-1 $\beta$, TNF- $\alpha$, PGE2), proteases and ROS produced by both synoviocytes and chondrocytes. ROS contribute to the inflammatoryrelated tissue degradation and are classically defined as partially reduced metabolites of oxygen that possess strong oxidizing capabilities. They are injurious, because they oxidize protein and lipid cellular constituents and damage the DNA. ROS function as signaling molecules that regulate cell growth, the adhesion of cells toward other cells, differentiation, senescence, and apoptosis $[85,86]$. The concept of chronic or prolonged ROS production is considered central to the progression of inflammatory disease. NO regulates the LPS activated signaling pathway, while the IL- $1 \beta$ activated transduction factors are more sensitive to $\mathrm{ONOO}^{-}$[87]. In synovial fibroblasts, ROS have also been shown to be required for signaling initiated through the integrin [88].
Oxidative stress, and especially $\mathrm{O}_{2}^{-}$, causes synoviocyte apoptosis in vitro through mitochondrial injury [86]. Similarly, $\mathrm{NO}^{-}$reduces the survival and induces cell death of $\mathrm{OA}$ synoviocytes by regulating mitochondrial functionality $[88,89]$. However, high NO levels can induce synovial cells apoptosis only when cell capacities to repair DNA damage are exceeded [90]. Furthermore, $\mathrm{NO}^{-}$induces OA synovial fibroblast apoptosis through activation of caspase-3, caspase-9 and upregulation of cyclooxygenase-2 (COX-2) expression. The $\mathrm{NO}^{-}$induced cell death is strongly associated with the production of $\mathrm{ONOO}^{-}, \mathrm{H}_{2} \mathrm{O}_{2}$ and $\mathrm{O}_{2}^{-}$[91] (Figure 4).

Soft tissues such as menisci and infrapatellar pad play a crucial role in knee OA pathogenesis. A meniscal tear can lead to knee OA, but knee OA can also lead to a spontaneous meniscal tear through breakdown and weakening of the meniscal structure [92]. iNOS and $\mathrm{NO}^{-}$production by meniscal cells is increased in $\mathrm{OA}$, as $\mathrm{NO}^{-}$augments apoptosis of meniscal cells via inhibition of autophagy through inactivation of c-Jun $\mathrm{N}$ terminal kinase 2 (JNK2) [93,94]. The infrapatellar fat pad is an emerging source of inflammatory and adipokines that contributes to knee OA progression [95]. It is known that adipose dysfunction and metabolic syndrome involves interactions between inflammatory pathways and ROS signaling [96]. Therefore, a link between oxidative stress and infrapatellar adipose tissue in knee $\mathrm{OA}$ is possible and needs further investigation.

Subchondral sclerosis is a major issue in OA pathogenesis and is involved in the pain generation in OA. In osteoblast of OA subchondral bone, hydroxinonenal (HNE) induces COX-2 expression and PGE2 release, by increasing the phosphorylation JNK2 and transcription factors binding factor-1(CREB-1) and activating transcription factor-2 (ATF-2) with a concomitant increase in the DNA-binding activity of CREB/ATF. Simultaneously, HNE decreased TNF- $\alpha$-induced interleukin-6 (IL-6) expression. These findings suggest that ROS-induced HNE may exert multiple effects on human OA osteoblasts by selective activation of signal transduction pathways and alteration of osteoblastic phenotype expression and pro-inflammatory mediator production [97,98].

In addition, in an ovine meniscectomy model of $\mathrm{OA}$, treatment with a $\mathrm{NO}^{-}$donor compound increases subchondral sclerosis, suggesting a role for $\mathrm{NO}^{-}$in the pain generation process in $\mathrm{OA}$ [99]. High levels of $\mathrm{NO}^{-}$inhibit osteoclast function and differentiation of osteoclasts from precursor cell types, as well as inhibiting osteoblast maturation and activity [100]. These observations suggest that oxidative stress has the potential be an important mediator of the subchondral bone changes seen in OA. 


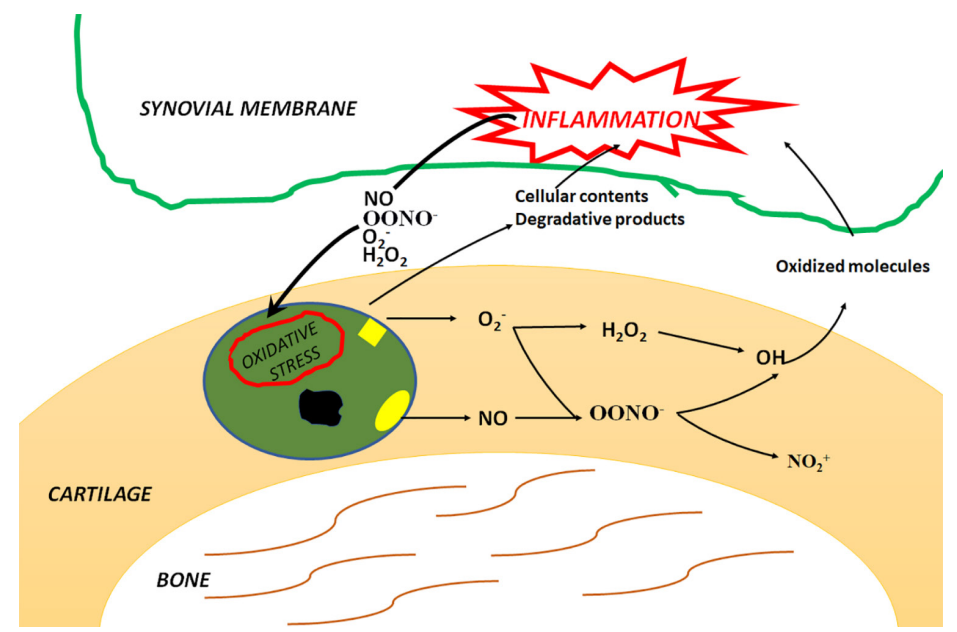

Figure 4. ROS produced by chondrocytes are nitric oxide $\left(\mathrm{NO}^{-}\right)$and superoxide anion $\left(\mathrm{O}_{2}^{-}\right)$that generate derivative radicals, including peroxynitrite $\left(\mathrm{ONOO}^{-}\right)$and hydrogen peroxide $\left(\mathrm{H}_{2} \mathrm{O}_{2}\right)$. Cellular response to ROS generation is dependent on the cellular redox status. In $\mathrm{OA}$, oxidative stress degrades not only cellular membranes and nucleic acids but also extracellular components, leading to impaired biological activity, changes in protein structure and accumulation of damaged proteins in the tissue. Degradation products and cellular content containing oxidized molecules contribute to the exacerbation of synovial inflammation and form a vicious circle constituted by newly formed ROS and degradation products.

\section{ROS and pain in OA}

NO is involved in perception and reduction of pain caused by OA via four different pathways: 1) the blood-flow pathway is normalized in the presence of NO, which may help to decrease ischemic pain; 2) the nerve transmission pathway, which decreases the irritation of the nerves in the synovium, bone, and soft tissues; 3) the opioid receptor pathway, which might stimulate the body's normal pain reduction pathways; 4) and the anti-inflammation pathway.

Small amounts of transiently produced $\mathrm{NO}^{-}$, perhaps produced by eNOS, could potentially decrease the pain associated with $\mathrm{OA}$ [101]. Both $\mathrm{H}_{2} \mathrm{O}_{2}$ and $\mathrm{ONOO}^{-}$ are involved in pain deriving from inflammation, mainly through COX2/PGE2 pathway [102].

\section{arthritis}

Experimental model used to induce osteo-

Animal models for OA are well established, and they serve as an important adjunct and surrogate for studies of OA in humans. These models provide a means to studying the pathophysiology of OA, and aid in the development of therapeutic agents and biological markers for diagnosing and prognosing disease. Small animal models are mainly used to study the pathogenesis and pathophysiology of the disease process. These models are relatively quicker, cheaper, and easier models to implement and study than the large animal models.

Chemically induced models mostly involve the injection of a toxic or inflammatory compound directly into the knee joint. This model can be used to study the effects of drugs on the inflammation or pain caused by these substances. Papain, sodium monoiodoacetate, quinolone, and collagenase are some of the chemicals employed to induce OA in animals. They eliminate the need for surgery and avoid possible infection issues in some animals. Their ease of induction and reproducibility are advantageous in designing short-term studies. Although less invasive than surgical models, chemical models have a unique pathophysiology which has no correlation to that of posttraumatic OA. This explains why they are mainly used to study the mechanism of pain and its use as a target for drug therapy.

Monosodium iodoacetate (MIA) is an inhibitor of glyceraldehyde-3-phosphate dehydrogenase activity, and causes dose-dependent cartilage degradation resembling the pathological changes of human osteoarthritis (OA).

MIA damages cartilage metabolism and leads to subchondral bone lesions and death of chondrocytes, and these OA-like lesions are similar to the pathologic changes seen in OA of humans [103]. MIA can result in cartilage matrix degradation and chondrocyte apoptosis in vivo and in vitro [104].

Chondrocyte impairment (involving apoptosis and necrosis) breaks the balance between anabolism and catabolism in the extracellular matrix and plays a critical role in the progression of OA. Necrotic and proapoptotic properties of MIA have been demonstrated in rat chondrocytes in vitro, and preliminary data have established that caspase-dependent apoptosis occurs in MIA-induced $\mathrm{OA}$ in the rat. MIA induces cellular necrosis by blocking the energy production pathways. There are two main pathways can lead to apoptotic process, that is, the receptor (extrinsic) 
pathway and the mitochondrial (intrinsic) pathway. In the extrinsic pathway, the stimulus of cell death receptors (Fas, TNF- $\alpha$, etc.) directly triggers caspase-3 initiating the following cascade reactions. In the intrinsic pathway, the apoptosis is initiated by response to a variety of stress signals. The classic signs of cell apoptosis are preceded by mitochondrial alterations including a decrease in energy production, a loss of membrane potential, an increase in the permeability of the mitochondrial membrane and a release of pro-apoptotic factors such as cytochrome C [105].

The molecular mechanisms of apoptosis induced by MIA in chondrocytes of rat resulted in the reduction of membrane potential, the release of cytochrome $\mathrm{c}$ from mitochondrion, the activation of caspase- 3 and finally the increase of apoptosis in primary rat chondrocytes.

ROS generation causes inflammation of articular cartilage and participates to apoptosis induction in $\mathrm{OA}$ $[105,106]$. MIA promoted an increase of ROS level and a reduction in membrane potential level and ROS formation is the cause of the membrane potential alterations in primary rat chondrocytes treated with MIA. MIA promoted ROS production, led to the depolarization of membrane potential, further enhanced the release of cytochrome $\mathrm{c}$ and increased caspase- 3 activity before leading to apoptosis. Also, oxidative stress plays an important upstream role in the apoptosis induced by MIA in primary rat chondrocytes [106].

\section{Concluding remarks}

The signaling pathways by which ROS contribute to OA pathophysiology are complex and not fully understood. The progression of OA from silent cartilage destruction to painful clinical presentation is an important subject to further investigation. Due to their chemical properties, free radicals are apt to mediate and amplify the characteristic sequence of joint degeneration in all tissues affected. These properties make them a crucial factor involved in all joint tissues disease development and for the inflammatory transformation of OA joints. Therapeutic outcomes of these mechanisms may be a promising area for further research that may lead to a better understanding and therefore arrest of disease progression.

\section{References}

1. Sellam J, Berenbaum F. The role of synovitis in pathophysiology and clinical symptoms of osteoarthritis. Nat Rev Rheumatol. 2010;6:625-635.

2. Loeser RF, Goldring SR, Scanzello CR, Goldring MB. Osteoarthritis: a disease of the joint as an organ. Arthritis Rheum. 2012;64:1697-1707.

3. Kapoor M, Martel-Pelletier J, Lajeunesse D, Pelletier JP, Fahmi H. Role of proinflammatory cytokines in the pathophysiology of osteoarthritis. Nat Rev Rheumatol. 2011;7:33-42.
4. Bijlsma JW, Berenbaum F, Lafeber FP. Osteoarthritis: an update with relevance for clinical practice. Lancet. 2011;377:2115-2126.

5. Sies H. Oxidative Stress: Introductory Remarks. London: Academic Press. 1985;1-8.

6. Forman HJ, Fukuto JM, Torres M. Redox signaling: thiol chemistry defines which reactive oxygen and nitrogen species can act as second messengers. Am J Physiol Cell Physiol. 2004;287:C246-C256.

7. Roehrs R, Guecheva TN, Saffi J, Henriques JAP. Redox sensitive targets in signaling cascades. In: ULBRA, editor. Free radicals and the cellular response to the oxidative stress. Universidade Luterana do Brasil: Canoas. 2004:161-84.

8. Li D, Xie G, Wang W. Reactive oxygen species: the 2-edged sword of osteoarthritis. Am J Med Sci. 2012;344:486-490.

9. Henrotin Y, Kurz B, Aigner T. Oxygen and reactive oxygen species in cartilage degradation: friends or foes? Osteoarthritis Cartilage. 2005;13:643-654.

10. Paździor M, Kiełczykowska M, Kurzepa J, LuchowskaKocot D, Kocot J, Musik I. The oxidative stress in knee osteoarthritis patients. An attempt of evaluation of possible compensatory effects occurring in the disease development. Medicina (Kaunas). 2019;55. E150. doi: 10.3390/ medicina55050150.

11. Hlavácek M. The role of synovial fluid filtration by cartilage in lubrication of synovial joints--IV. Squeezefilm lubrication: the central film thickness for normal and inflammatory synovial fluids for axial symmetry under high loading conditions. J Biomech. 1995;28:1199-1205.

12. Gomez JE, Thurston GB. Comparison of the oscillatory shear viscoelasticity and composition of pathological synovial fluids. Biorheology. 1993;30:409-427.

13. Adam-Vizi V, Chinopoulos C. Bioenergetics and the formation of mitochondrial reactive oxygen species. Trends Pharmacol Sci. 2006;27:639-645.

14. Turrens JF. Mitochondrial formation of reactive oxygen species. J Physiol. 2003;522(Pt 2):335-344.

15. Chance B, Williams GR. Respiratory enzymes in oxidative phosphorylation. I. Kinetics of oxygen utilization. J Biol Chem. 1955;217:383-393.

16. Drevet S, Gavazzi G, Grange L, Dupuy C, Lardy B. Reactive oxygen species and NADPH oxidase 4 involvment in osteoarthritiss. Exp Gerontol. 2018;111:107-117.

17. Gibson JS, McCartney D, Sumpter J, Fairfax TP, Milner PI, Edwards HL, et al. Rapid effects of hypoxia on $\mathrm{H}+$ homeostasis in articular chondrocytes. Pflugers Arch. 2009;458:1085-1092.

18. Fattman CL, Schaefer LM, Oury TD. Extracellular superoxide dismutase in biology and medicine. Free Radic Biol Med. 2003;35:236-256.

19. Nathan C. Nitric oxide as a secretory product of mammalian cells. FASEB J. 1992;6:3051-3064.

20. Squadrito GL, Pryor WA. Oxidative chemistry of nitric oxide: the roles of superoxide, peroxynitrite, and carbon dioxide. Free Radic Biol Med. 1998;25:392-403.

21. Babior BM. NADPH oxidase. Curr Opin Immunol. 
2004; 16:42-47.

22. Halliwell B. Reactive oxygen species in living systems: source, biochemistry, and role in human disease. Am J Med. 1991;91:14S-22S.

23. Bedard K, Krause KH. The NOX family of ROS-generating NADPH oxidases: physiology and pathophysiology. Physiol Rev. 2007;87:245-313.

24. Francis SH, Busch JL, Corbin JD, Sibley D. cGMPdependent protein kinases and cGMP phosphodiesterases in nitric oxide and cGMP action. Pharmacol Rev. 2010;62:525563.

25. Hanafy KA, Krumenacker JS, Murad F. NO, nitrotyrosine, and cyclic GMP in signal transduction. Med Sci Monit. 2001;7:801-819.

26. Torres J, Cooper CE, Wilson MT. A common mechanism for the interaction of nitric oxide with the oxidized binuclear centre and oxygen intermediates of cytochrome c oxidase. J Biol Chem.1998;273:8756-8766.

27. Hess DT, Matsumoto A, Kim SO, Marshall HE, Stamler JS. Protein S-nitrosylation: purview and parameters. Nat Rev Mol Cell Biol. 2005;6:150-166.

28. Stamler JS, Lamas S, Fang FC. Nitrosylation. the prototypic redox-based signaling mechanism. Cell. 2001:106;675-683.

29. Rahmati M, Nalesso G, Mobasheri A, Mozafari M. Aging and osteoarthritis: control role of extracellular matrix. Ageing Res Rev. 2017;40:20-30.

30. Henrotin Y, Deby-Dupont G, Deby C, De Bruyn M, Lamy M, Franchimont P. Production of active oxygen species by isolated human chondrocytes. Br J Rheumatol. 1993;32:562567.

31. Rathakrishnan C, Tiku K, Raghavan A, Tiku ML. Release of oxygen radicals by articular chondrocytes: a study of luminol-dependent chemiluminescence and hydrogen peroxide secretion. J Bone Miner Res. 1992;7:1139-1148.

32. Tiku ML, Liesch JB, Robertson FM. Production of hydrogen peroxide by rabbit articular chondrocytes. Enhancement by cytokines. J Immunol. 1990;145:690-696.

33. Henrotin YE, Bruckner P, Pujol JP. The role of reactive oxygen species in homeostasis and degradation of cartilage. Osteoarthritis Cartilage. 2003;11:747-755.

34. Altay MA, Ertürk C, Bilge A, Yapti M, Levent A, Aksoy N. Evaluation of prolidase activity and oxidative status in patients with knee osteoarthritis: relationships with radiographic severity and clinical parameters. Rheumatol Int. 2015;35:1725-1731.

35. Ertürk C, Altay MA, Selek S, Koçyiğit A. Paraoxonase-1 activity and oxidative status in patients with knee osteoarthritis and their relationship with radiological and clinical parameters. Scand J Clin Lab Invest. 2012;72:433-439.

36. Altindag O, Erel O, Aksoy N, Selek S, Celik H, Karaoglanoglu M. Increased oxidative stress and its relation with collagen metabolism in knee osteoarthritis. Rheumatol Int. 2007;27:339-344.

37. Karan A, Karan MA, Vural P, Erten N, Taşçioğlu C, Aksoy $\mathrm{C}$, et al. Synovial fluid nitric oxide levels in patients with knee osteoarthritis. Clin Rheumatol. 2003;22:397-399.
38. Sakurai H, Kohsaka H, Liu MF, Higashiyama H, Hirata Y, Kanno K, et al. Nitric oxide production and inducible nitric oxide synthase expression in inflammatory arthritides. J Clin Invest. 1995;96:2357-2363.

39. Ersoy Y, Ozerol E, Baysal O, Temel I, MacWalter RS, Meral U, et al. Serum nitrate and nitrite levels in patients with rheumatoid arthritis, ankylosing spondylitis, and osteoarthritis. Ann Rheum Dis. 2002;61:76-78.

40. Nemirovskiy OV, Radabaugh MR, Aggarwal P, FunckesShippy CL, Mnich SJ, Meyer DM, et al. Plasma 3-nitrotyrosine is a biomarker in animal models of arthritis: pharmacological dissection of iNOS' role in disease. Nitric Oxide. 2009;20:150-156.

41. Ostalowska A, Birkner E, Wiecha M, Kasperczyk S, Kasperczyk A, Kapolka D, et al. Lipid peroxidation and antioxidant enzymes in synovial fluid of patients with primary and secondary osteoarthritis of the knee joint. Osteoarthritis Cartilage. 2006;14:139-145.

42. Carlo MD Jr, Loeser RF. Increased oxidative stress with aging reduces chondrocyte survival: correlation with intracellular glutathione levels. Arthritis Rheum. 2003;48:3419-3430.

43. Regan EA, Bowler RP, Crapo JD. Joint fluid antioxidants are decreased in osteoarthritic joints compared to joints with macroscopically intact cartilage and subacute injury. Osteoarthritis Cartilage. 2008;16:515-521.

44. Fernandez-Moreno M, Soto-Hermida A, Pertega S, Oreiro N, Fernandez-Lopez C, Rego-Perez I, et al. Mitochondrial DNA (mtDNA) haplogroups and serum levels of anti-oxidant enzymes in patients with osteoarthritis. BMC Musculoskelet Disord. 2011;12:264. doi: 10.1186/1471-2474-12-264.

45. Soran N, Altindag O, Cakir H, Celik H, Demirkol A, Aksoy $\mathrm{N}$. Assessment of paraoxonase activities in patients with knee osteoarthritis. Redox Rep. 2008;13:194-198.

46. Hiran TS, Moulton PJ, Hancock JT. Detection of superoxide and NADPH oxidase in porcine articular chondrocytes. Free Radic Biol Med. 1997;23:736-743.

47. Moulton PJ, Goldring MB, Hancock JT. NADPH oxidase of chondrocytes contains an isoform of the gp91phox subunit. Biochem J. 1998;329(Pt 3):449-451.

48. Grange L, Nguyen MV, Lardy B, Derouazi M, Campion $\mathrm{Y}$, Trocme $\mathrm{C}$, et al. NAD(P)H oxidase activity of Nox4 in chondrocytes is both inducible and involved in collagenase expression. Antioxid Redox Signal. 2006;8:1485-1496.

49. Wegner AM, Campos NR, Robbins MA, Haddad AF, Cunningham HC, Yik JHN, et al. Acute changes in NADPH oxidase 4 in early post-traumatic osteoarthritis. J Orthop Res. 2019;37:2429-2436.

50. Lee RB, Urban JP. Evidence for a negative Pasteur effect in articular cartilage. Biochem J. 1997;321(Pt 1):95-102.

51. Koike M, Nojiri H, Ozawa Y, Watanabe K, Muramatsu $\mathrm{Y}$, Kaneko $\mathrm{H}$, et al. Mechanical overloading causes mitochondrial superoxide and SOD2 imbalance in chondrocytes resulting in cartilage degeneration. Sci Rep. 2015;5:11722. doi: 10.1038/srep11722.

52. Beecher BR, Martin JA, Pedersen DR, Heiner AR, Buckwalter JA. Antioxidants block cyclic loading induced chondrocyte death. Iowa Orthop J. 2007;27:1-8. 
53. Moulton PJ, Hiran TS, Goldring MB, Hancock JT. Detection of protein and mRNA of various components of the NADPH oxidase complex in an immortalized human chondrocyte line. Br J Rheumatol. 1997;36:522-529.

54. Mathy-Hartert M, Deby-Dupont GP, Reginster JY, Ayache N, Pujol JP, Henrotin YE. Regulation by reactive oxygen species of interleukin-1beta, nitric oxide and prostaglandin $\mathrm{E}(2)$ production by human chondrocytes. Osteoarthritis Cartilage. 2002;10:547-555.

55. Palmer RM, Hickery MS, Charles IG, Moncada S, Bayliss MT. Induction of nitric oxide synthase in human chondrocytes. Biochem Biophys Res Commun. 1993;193:398-405.

56. Yin W, Park JI, Loeser RF. Oxidative stress inhibits insulin-like growth factor-I induction of chondrocyte proteoglycan synthesis through differential regulation of phosphatidylinositol 3-Kinase-Akt and MEK-ERK MAPK signaling pathways. J Biol Chem. 2009;284:31972-31981.

57. Rosa SC, Judas F, Lopes MC, Mendes AF. Nitric oxide synthase isoforms and NF-kappaB activity in normal and osteoarthritic human chondrocytes: regulation by inducible nitric oxide. Nitric Oxide. 2008;19:276-283.

58. Beecher BR, Martin JA, Pedersen DR, Heiner AR, Buckwalter JA. Antioxidants block cyclic loading induced chondrocyte death. Iowa Orthop J. 2007;27:1-8.

59. Yu SM, Kim SJ. The thymoquinone-induced production of reactive oxygen species promotes dedifferentiation through the ERK pathway and inflammation through the p38 and PI3K pathways in rabbit articular chondrocytes. Int $\mathrm{J}$ Mol Med. 2015;35:325-332.

60. Blanco FJ, Guitian R, Vázquez-Martul E, de Toro FJ, Galdo F. Osteoarthritis chondrocytes die by apoptosis. A possible pathway for osteoarthritis pathology. Arthritis Rheum. 1998;41:284-289.

61. Aigner T, Kim HA. Apoptosis and cellular vitality: issues in osteoarthritic cartilage degeneration. Arthritis Rheum. 2002;46:1986-1996.

62. Maneiro E, López-Armada MJ, de Andres MC, Caramés B, Martín MA, Bonilla A, et al. Effect of nitric oxide on mitochondrial respiratory activity of human articular chondrocytes. Ann Rheum Dis. 2005;64:388-395.

63. Blanco FJ, Ochs RL, Schwarz H, Lotz M. Chondrocyte apoptosis induced by nitric oxide. Am J Pathol. 1995;146:7585 .

64. Hashimoto S, Takahashi K, Amiel D, Coutts RD, Lotz M. Chondrocyte apoptosis and nitric oxide production during experimentally induced osteoarthritis. Arthritis Rheum. 1998;41:1266-1274.

65. Notoya K, Jovanovic DV, Reboul P, Martel-Pelletier J, Mineau F, Pelletier JP. The induction of cell death in human osteoarthritis chondrocytes by nitric oxide is related to the production of prostaglandin E2 via the induction of cyclooxygenase-2. J Immunol. 2000;165:3402-3410.

66. Pelletier JP, Fernandes JC, Jovanovic DV, Reboul P, MartelPelletier J. Chondrocyte death in experimental osteoarthritis is mediated by MEK $1 / 2$ and p38 pathways: role of cyclooxygenase- 2 and inducible nitric oxide synthase. J Rheumatol. 2001;28:2509-2519.
67. Fioravanti A, Cantarini L, Chellini F, Manca D, Paccagnini E, Marcolongo R, et al. Effect of hyaluronic acid (MW 500-730 $\mathrm{kDa}$ ) on proteoglycan and nitric oxide production in human osteoarthritic chondrocyte cultures exposed to hydrostatic pressure. Osteoarthritis Cartilage. 2005;13:688-696.

68. Frenkel SR, Clancy RM, Ricci JL, Di Cesare PE, Rediske JJ, Abramson SB. Effects of nitric oxide on chondrocyte migration, adhesion, and cytoskeletal assembly. Arthritis Rheum. 1996;39:1905-1912.

69. van Lent PL, Nabbe KC, Blom AB, Sloetjes A, Holthuysen AE, Kolls J, et al. NADPH-oxidase-driven oxygen radical production determines chondrocyte death and partly regulates metalloproteinase-mediated cartilage matrix degradation during interferon-gamma-stimulated immune complex arthritis. Arthritis Res Ther. 2005;7:R885-R895.

70. Kühn K, Shikhman AR, Lotz M. Role of nitric oxide, reactive oxygen species, and p38 MAP kinase in the regulation of human chondrocyte apoptosis. J Cell Physiol. 2003;197:379387.

71. Pelletier JP, Lascau-Coman V, Jovanovic D, Fernandes JC, Manning P, Connor JR, et al. Selective inhibition of inducible nitric oxide synthase in experimental osteoarthritis is associated with reduction in tissue levels of catabolic factors. J Rheumatol. 1999;26:2002-2014.

72. Amin AR, Di Cesare PE, Vyas P, Attur M, Tzeng E, Billiar $\mathrm{TR}$, et al. The expression and regulation of nitric oxide synthase in human osteoarthritis-affected chondrocytes: evidence for up-regulated neuronal nitric oxide synthase. J Exp Med. 1995;182:2097-2102.

73. van den Berg WB, van de Loo F, Joosten LA, Arntz OJ. Animal models of arthritis in NOS2-deficient mice. Osteoarthritis Cartilage. 1999;7:413-415.

74. Mendes AF, Carvalho AP, Caramona MM, Lopes MC. Role of nitric oxide in the activation of NF-kappaB, AP-1 and NOS II expression in articular chondrocytes. Inflamm Res. 2002;51:369-375.

75. Rosa SC, Judas F, Lopes MC, Mendes AF. Nitric oxide synthase isoforms and NF-kappaB activity in normal and osteoarthritic human chondrocytes: regulation by inducible nitric oxide. Nitric Oxide. 2008;19:276-283.

76. Del Carlo M Jr, Loeser RF. Nitric oxide-mediated chondrocyte cell death requires the generation of additional reactive oxygen species. Arthritis Rheum. 2002;46:394-403.

77. Johnson K, Jung A, Murphy A, Andreyev A, Dykens J, Terkeltaub R. Mitochondrial oxidative phosphorylation is a downstream regulator of nitric oxide effects on chondrocyte matrix synthesis and mineralization. Arthritis Rheum. 2000;43:1560-1570.

78. Migita K, Yamasaki S, Kita M, Ida H, Shibatomi K, Kawakami A, et al. Nitric oxide protects cultured rheumatoid synovial cells from Fas-induced apoptosis by inhibiting caspase-3. Immunology. 2001;103:362-367.

79. Liang Q, Wang XP, Chen TS. Resveratrol protects rabbit articular chondrocyte against sodium nitroprusside-induced apoptosis via scavenging ROS. Apoptosis. 2014;19:13541363.

80. Roos WP, Kaina B. DNA damage-induced cell death by 
apoptosis. Trends Mol Med. 2006;12:440-450.

81. Gao Y, Liu S, Huang J, Guo W, Chen J, Zhang L, et al. The ECM-cell interaction of cartilage extracellular matrix on chondrocytes. Biomed Res Int. 2014;2014:648459.

82. Oh M, Fukuda K, Asada S, Yasuda Y, Tanaka S. Concurrent generation of nitric oxide and superoxide inhibits proteoglycan synthesis in bovine articular chondrocytes: involvement of peroxynitrite. J Rheumatol. 1998;25:21692174.

83. Englund M, Guermazi A, Lohmander SL. The role of the meniscus in knee osteoarthritis: a cause or consequence? Radiol Clin North Am. 2009;47:703-712.

84. Shen C, Yan J, Erkocak OF, Zheng XF, Chen XD. Nitric oxide inhibits autophagy via suppression of JNK in meniscal cells. Rheumatology (Oxford). 2014;53:1022-1033.

85. Hancock CM, Riegger-Krugh C. Modulation of pain in osteoarthritis: the role of nitric oxide. Clin J Pain. 2008;24:353-365.

86. Frenkel SR, Clancy RM, Ricci JL, Di Cesare PE, Rediske JJ, Abramson SB. Effects of nitric oxide on chondrocyte migration, adhesion, and cytoskeletal assembly. Arthritis Rheum. 1996;39:1905-1912.

87. López-Armada MJ, Caramés B, Martín MA, Cillero-Pastor B, Lires-Dean M, Fuentes-Boquete I, et al. Mitochondrial activity is modulated by TNFalpha and IL-1beta in normal human chondrocyte cells. Osteoarthritis Cartilage. 2006;14:1011-1022.

88. Wang ZQ, Porreca F, Cuzzocrea S, Galen K, Lightfoot R, Masini E, et al. A newly identified role for superoxide in inflammatory pain. J Pharmacol Exp Ther. 2004;309:869878.

89. Cedergren J, Forslund T, Sundqvist T, Skogh T. Inducible nitric oxide synthase is expressed in synovial fluid granulocytes. Clin Exp Immunol. 2002;130:150-155.

90. Jovanovic DV, Mineau F, Notoya K, Reboul P, MartelPelletier J, Pelletier JP. Nitric oxide induced cell death in human osteoarthritic synoviocytes is mediated by tyrosine kinase activation and hydrogen peroxide and/or superoxide formation. J Rheumatol. 2002;29:2165-2175.

91. Shi Q, Vaillancourt F, Côté V, Fahmi H, Lavigne P, Afif $\mathrm{H}$, et al. Alterations of metabolic activity in human osteoarthritic osteoblasts by lipid peroxidation end product 4-hydroxynonenal. Arthritis Res Ther. 2006;8:R159.

92. Korkmaz M, Turkmen R, Demirel HH, Saritas ZK. Effect of boron on the repair of osteocondral defect and oxidative stress in rats: an experimental study. Biol Trace Elem Res. 2019; 187:425-433.

93. Cake MA, Read RA, Appleyard RC, Hwa SY, Ghosh P. The nitric oxide donor glyceryl trinitrate increases subchondral bone sclerosis and cartilage degeneration following ovine meniscectomy. Osteoarthritis Cartilage. 2004;12:974-981.

94. Evans DM, Ralston SH. Nitric oxide and bone. J Bone Miner
Res. 1996;11:300-305.

95. Kheradmand F, Werner E, Tremble P, Symons M, Werb Z. Role of Rac 1 and oxygen radicals in collagenase-1 expression induced by cell shape change. Science. 1998;280:898-902.

96. Galleron S, Borderie D, Ponteziere C, Lemarechal H, Jambou M, Roch-Arveiller M, et al. Reactive oxygen species induce apoptosis of synoviocytes in vitro. Alpha-tocopherol provides no protection. Cell Biol Int. 1999;23:637-642.

97. Cillero-Pastor B, Martin MA, Arenas J, López-Armada MJ, Blanco FJ. Effect of nitric oxide on mitochondrial activity of human synovial cells. BMC Musculoskelet Disord. 2011;12:42.

98. Borderie D, Hilliquin P, Hernvann A, Lemarechal H, Menkes CJ, Ekindjian OG. Apoptosis induced by nitric oxide is associated with nuclear p53 protein expression in cultured osteoarthritic synoviocytes. Osteoarthritis Cartilage. 1999;7:203-213.

99. Studer RK, Levicoff E, Georgescu H, Miller L, Jaffurs D, Evans $\mathrm{CH}$. Nitric oxide inhibits chondrocyte response to IGF-I: inhibition of IGF-IRbeta tyrosine phosphorylation. Am J Physiol Cell Physiol. 2000;279:C961-C969.

100. Mateos J, De la Fuente A, Lesende-Rodriguez I, FernándezPernas P, Arufe MC, Blanco FJ. Lamin A deregulation in human mesenchymal stem cells promotes an impairment in their chondrogenic potential and imbalance in their response to oxidative stress. Stem Cell Res. 2013;11:1137-1148.

101. Guingamp C, Gegout-Pottie P, Philippe L, Terlain B, Netter P, Gillet P. Mono-iodoacetate-induced experimental osteoarthritis: a dose-response study of loss of mobility, morphology, and biochemistry. Arthritis Rheum. 1997;40:1670-1679.

102. Pelletier JP, Jovanovic DV, Lascau-Coman V, Fernandes JC, Manning PT, Connor JR, et al. Selective inhibition of inducible nitric oxide synthase reduces progression of experimental osteoarthritis in vivo: possible link with the reduction in chondrocyte apoptosis and caspase 3 level. Arthritis Rheum. 2000;43:1290-1299.

103. Peters HC, Otto TJ, Enders JT, Jin W, Moed BR, Zhang $Z$. The protective role of the pericellular matrix in chondrocyte apoptosis. Tissue Eng Part A. 2011;17:2017-2024. Mouser VHM, Dautzenberg NMM, Levato R, van Rijen MHP, Dhert WJA, Malda J, et al. Ex vivo model unravelling cell distribution effect in hydrogels for cartilage repair. ALTEX. 2018;35:65-76.

104. Hashimoto S, Takahashi K, Ochs RL, Coutts RD, Amiel D, Lotz M. Nitric oxide production and apoptosis in cells of the meniscus during experimental osteoarthritis. Arthritis Rheum. 1999;42:2123-2131.

105. Dröge W. Free radicals in the physiological control of cell function. Physiol Rev. 2002;82:47-95.

106. Thannickal VJ, Fanburg BL. Reactive oxygen species in cell signaling. Am J Physiol Lung Cell Mol Physiol. 2000;279:L1005-L1028. 